\title{
O BEM COMUM COMO VALOR E O ACESSO À JUSTIÇA COMO COMPROMISSO: IMPLICAÇÕES SOBRE O PROCESSO CIVIL
}

\section{THE COMMON GOOD AS VALUE AND ACCESS TO JUSTICE AS COMMITMENT: IMPLICATIONS ON THE CIVIL PROCESS}

\begin{abstract}
JANAÍNA MACHADO STURZA
Pós doutora em Direito pelo Programa de Pós Graduação em Direito da Universidade do Vale do Rio dos Sinos - UNISINOS. Doutora em Direito pela Escola Internacional de Doutorado em Direito Tullio Ascarelli, da Universidade de Roma Tre - Itália. Mestre em Direito pela Universidade de Santa Cruz do Sul - UNISC. Especialista em Demandas Sociais e Políticas Públicas também pela UNISC. Graduada em Direito pela UNISC. Foi professora no Centro Universitário Ritter dos Reis - Uniritter, lecionando na graduação em Direito e no Programa de Pós Graduação em Direito Mestrado. Foi professora nos cursos de graduação em Direito na IMED (Passo Fundo); na ESADE (hoje FADERGS - Porto Alegre), na UNIFRA (Santa Maria) e na Faculdade Dom Alberto (Santa Cruz do Sul). Atualmente é professora na Universidade Regional do Noroeste do Estado do Rio Grande do Sul - UNIJUí, lecionando na graduação em Direito e no Programa de Pós Graduação em Direito - Mestrado e Doutorado.
\end{abstract}

\section{KARINNE EMANOELA GOETTEMS DOS SANTOS}

Doutora em Direito pela UNISINOS (2015). Mestrado em Direito pela UNISINOS (2006). Especialização em Direito Processual Civil pela PUCRS (2001). É Professora Adjunta da Faculdade de Direito da Universidade Federal de Pelotas (UFPEL). Coordenadora do Serviço de Assistência Jurídica da UFPEL. Professora da Graduação e da Pós-Graduação em Direito - Mestrado. 


\section{RESUMO}

Objetivo: Este estudo tem como objetivo fomentar a reflexão sobre o atual cenário de conflitos sociais, no qual se encontra a sociedade contemporânea, destacando a importância do acesso à Justiça por meio de um processo civil constitucionalmente adequado, na perspectiva do bem comum.

Metodologia: A pesquisa converge para a importância da adaptação dos procedimentos judiciais à realidade social, por meio de um estudo bibliográfico norteado pelo método hipotético dedutivo, apresentando a hermenêutica filosófica gadameriana e as perspectivas de Mauro Cappelletti como principais referenciais teóricos.

Resultados: Entender a sociedade a partir de um contexto conflituoso implica assumir uma nova postura diante da complexidade social e da efetivação do necessário processo de transformação na perspectiva de bem comum e, essencialmente, de acesso à Justiça como compromisso. Na órbita do processo civil, esse compromisso torna-se ainda mais evidente com a superveniência do novo Código de Processo.

Contribuições: A demonstração de que a efetividade dos direitos fundamentais e a consagração da cidadania perpassam necessariamente por um processo civil constitucionalmente adequado, o qual deve e é capaz de adaptar-se às complexidades da vida social contemporânea.

Palavras-chave: bem comum; cidadania; acesso à Justiça; processo constitucionalmente adequado.

\section{ABSTRACT}

Objective: To encourage reflection on the current scenario of social conflicts in which contemporary society is situated, highlighting the importance of access to Justice by way of a constitutionally adequate civil process in the perspective of the common good. Methodology: The research converges to the importance of adapting judicial procedures to social reality by way of a bibliographic study guided by the hypothetical deductive method, presenting Gadamerian philosophical hermeneutics and the perspectives of Mauro Cappelletti as main theoretical references.

Results: To understand the society from a conflictual context implies taking a new stance before social complexity and the implementation of the necessary transformation process in the perspective of the common good and, essentially, access to Justice as a commitment. In the orbit of civil proceedings this commitment becomes even more evident upon the supervenience of the new Code of Procedure. 
Contributions: The demonstration that the effectiveness of fundamental rights and the implementation of citizenship necessarily pass through a constitutionally adequate civil process, which must and is capable of adapting to the complexities of contemporary social life.

Keywords: Common good; citizenship; access to Justice; appropriate constitutional process.

\section{INTRODUÇÃO}

Dentre os valores referidos pelo art. 8o do novo Código de Processo Civil (Lei 13.105/2015) para balizar a aplicação do ordenamento jurídico, encontram-se os fins sociais, as exigências do bem comum e o resguardo e promoção da dignidade da pessoa humana, reproduzindo, ainda, o direcionamento antes dado pelo art. $5^{\circ}$ da Lei de Introdução às normas do Direito Brasileiro (Lei 4.657/42, agora renovada pela Lei 12.376/2010).

$\mathrm{Na}$ perspectiva do novo CPC, o bem comum ganha status de norma fundamental do processo civil, ao lado de outras normas como a efetividade da prestação jurisdicional, presente no art.4ำ, e passa, portanto, a integrar um padrão constitucional como referência de acesso à justiça (MARINONI, 2013, p.84). O apelo constitucional do novo Código, já no primeiro capítulo, reforça, portanto, a necessidade de uma avaliação do acesso à justiça, na perspectiva daqueles valores, especialmente diante de um quadro social de extrema desigualdade, ao tempo de uma promessa constitucional voltada para a promoção do bem de todos sem distinção (art.3ㅜㅡ, inciso IV da CF/88) e anda diante de um cenário jurisdicional de intensa litigiosidade, que precariza a prestação jurisdicional.

Diante desse contexto, ainda e sempre na perspectiva de Mauro Cappelletti, é preciso avaliar se o acesso à justiça na atualidade, dentro dos escopos constitucionais, está sendo exercido de forma plena e paritária, o que inclui o acesso da classe menos favorecida, a adequação dos ritos processuais à natureza dos direitos difusos coletivos e, por fim, a adoção de procedimentos alternativos à 
jurisdição na perspectiva do que Cappelletti chamou de uma ampla reforma (CAPPELLETTI; GARTH, 1988, p.31).

Cabe, portanto, avaliar se, após quatro décadas depois de formuladas, as perspectivas do processualista florentino foram internalizadas na nossa cultura jurídica, o que se pretende fazer a partir da compreensão de bem comum e do resguardo da dignidade do cidadão na concretização do acesso à justiça.

Como sedimentar o bem comum como norma fundamental de aplicação do ordenamento jurídico? O que é, afinal, bem comum? Por que esse olhar? Por que é importante analisar o extrato social quando se pretende debater as condições de acesso à justiça na contemporaneidade? Por que é relevante compreender o conflito social para avaliar a adequação do ritual adotado para sua "pacificação"?

Nessa linha, a avaliação recai sobre os procedimentos disponibilizados pelo ordenamento jurídico, seja sobre sua adequação frente à natureza de cada conflito, seja sobre o compromisso de tais procedimentos frente aos valores constitucionais que permeiam o acesso à justiça, com destaque para a materialização do bem comum.

Para além das teorias de premissa maior e premissa menor e para além do princípio da substanciação que separa fato de direito na teoria dos elementos da ação, este trabalho propõe uma reflexão sobre acesso à justiça e cidadania, sobre processo e bem comum, sobre jurisdição e sociedade. Para tanto, não é possível direcionar esse olhar sem considerar ou materializar o óbvio, que está nas ruas, nas famílias, no trabalho e na economia, com todas as suas contingências e circunstâncias de tempo e espaço. O direito dos conceitos e dos códigos teve seu momento. O século XXI exige bem mais do que isso. É preciso, sobretudo, olhar para o cidadão e o conflito vivenciado por ele.

E para atender a essa perspectiva, o artigo direciona sua atenção sobre os indicadores sociais do IBGE e do último PNUD, para depois avançar para a análise dos rituais de solução de conflitos disponíveis pelo ordenamento jurídico e, na perspectiva de Hans-Georg Gadamer e Cappelletti, apresentar o bem comum como fator de distinção para a efetividade do acesso à justiça, especialmente a partir da edição do novo Código de Processo Civil em março de 2015. 
Com essa perspectiva, através de um estudo bibliográfico norteado pelo método hipotético dedutivo, este texto tem como objetivo fomentar a reflexão acerca do atual cenário de resolução dos conflitos sociais, destacando a importância do acesso à justiça como reflexo do exercício pleno da cidadania, na defesa de um processo civil comprometido com a promoção do bem comum. A partir disso, esperarse demonstrar que a efetividade dos direitos fundamentais e a consagração da cidadania perpassam necessariamente por um processo civil constitucionalmente adequado, o qual deve e é capaz de se adaptar às diferenças na contemporaneidade.

\section{PARA COMEÇAR: UM OLHAR SOBRE A FACTICIDADE}

No ambiente jurisdicional, a linha propulsora das reformas processuais especialmente na década que antecedeu ao novo Código de Processo Civil-, focada para acelerar os ritos processuais, seguiu uma cartilha dogmática e conceitual, detentora de um discurso liberal comprometido especialmente com a cultura jurídica dos séculos passados.

De acordo com Boaventura de Sousa Santos, com diferentes níveis de intensidade, as reformas do sistema judiciário em todo mundo ocorreram, muito seletivamente, nos setores que melhor servem aos interesses econômicos, deixando de fora todos os outros, com clara orientação de eficiência e da necessária celeridade (CAPPELLETTI; GARTH 2011, p.34).

É também valiosa e precisa a observação de Ovídio Baptista da Silva, ao afirmar que "Na galáxia do capitalismo, com seus pressupostos éticos, políticos e econômicos, seria ingênuo sonhar com alguma transformação real do direito processual" (CAPPELLETTI; GARTH 2006, p.306). Diante disso, há um evidente paradoxo entre as ideologias latentes e propulsoras das reformas e os valores que as próprias reformas acabaram por positivar.

Sob um outro aspecto, o caminho da abstração em prol da eficiência manifesta um desprezo pela realidade social, o que torna inatingível a materialização de valores que orbitam justamente em torno de uma justiça mais humanitária. E o melhor 
depoimento para conduzir essa reflexão vem também de Ovídio Baptista da Silva, que testemunhou a evolução da legislação processual na segunda metade do século XX. Ovídio revelava sua singular preocupação acerca da necessidade de uma jurisdição compatível com a realidade contemporânea, bem como sua angústia frente à "falta de compreensão adequada aos fatores culturais que nos aprisionam, fazendo com que andemos em círculos, sem que nenhum progresso efetivo se tenha obtido" (CAPPELLETTI; GARTH 2006, no prefácio).

Nesse sentido, enquanto a vida social parece ocupar um outro patamar distante do ordenamento jurídico vigente, além de restar mantida a separação clássica e enfadonha entre questão de fato e questão de direito (SANTOS, 2006), é possível antecipar que o exercício efetivo dos direitos fundamentais ocupam muito mais a academia do que de fato ocorre na vida em sociedade.

Olhar para esse paradigma e, portanto, desejar observar com honestidade a efetividade do acesso à justiça, a partir de um modelo de jurisdição, requer necessariamente uma atenção especial à faticidade, ínsita a uma sociedade complexa, desigual e individualista. Na perspectiva hermenêutica de Gadamer, a facticidade, como estrutura essencial do dasein, deve encontrar sua marca na compreensão da tradição histórica, ou seja, a estrutura universal da compreensão atinge sua concretude na compreensão histórica, uma vez que os vínculos concretos de costume e tradição e suas correspondentes possibilidades de futuro tornam-se operantes na própria compreensão (GADAMER, 2004, p.353), pois "só podemos falar da história por sermos nós mesmo seres históricos” (GADAMER, 2003. p.43).

Integram, portanto, essa realidade, trabalhadores, consumidores ou simplesmente cidadãos membros de algum núcleo familiar, que vão se deparar, a todo momento da vida cotidiana, com as contingências da exploração no ambiente de trabalho; com as experiências das desavenças familiares de lares vazios ou com as conturbadas relações de vizinhança (LIPOVETSKI, 2005, p.59-60); com as frustrações decorrentes das abusividades cometidas por fornecedores de bens e serviços que impõem contratos onerosos e danosos às suas rendas, à sua saúde ou ainda sobre a sua qualidade de vida. Ainda, na dura realidade do cotidiano, esse olhar vai encontrar muitos trabalhadores que executam os serviços menos desejosos, mas 
necessários à rotina urbana. Neste contexto, não ter emprego deve ser, ainda, a situação menos desejada).

Esse olhar vai encontrar, ainda, no layout paradoxal das cidades, de um lado moradias precárias e em desacordo com aquilo que se pretende digno em nível de direitos humanos e fundamentais, ou ainda pessoas cujo "domicílio" é a própria rua, com o agravante de, por vezes, estarem acompanhadas de crianças e adolescentes; de outro, no polo extremo deste layout, observa-se uma distinta parcela de cidadãos com trabalho e rendimentos "dignos", que consomem bens e serviços destinados a poucos.

A narrativa sintoniza-se com os indicadores provenientes do Programa das Nações Unidas para o Desenvolvimento e do Instituto Brasileiro de Geografia e Estatística. Para além do aspecto quantitativo, o Índice de Desenvolvimento Humano (IDH) e o nível de concentração de renda (Coeficiente de Gini) fornecem uma amostra muito clara da vida contemporânea, seguindo o traço da desigualdade em países como o Brasil e suas implicações sobre o exercício da cidadania.

Com relação ao trabalho e à ocupação da população, o IBGE divulgou em 2016, através da pesquisa "Síntese dos Indicadores Sociais: uma análise das condições de vida da população brasileira", que a população desocupada no Brasil em 2015 é de 9,8 milhões de pessoas, dos quais 42\% encontra-se na faixa de 16 aos 24 anos (IBGE, 2016, p.70). Para a população ocupada, a renda média mensal é de $\mathrm{R} \$ 1.808,00$ (IBGE, 2016, p.78). Com relação à concentração de renda, os números são desconcertantes. Para o IBGE, cerca de $10 \%$ das pessoas com maiores rendimentos concentra $40,5 \%$ dos rendimentos em 2015 e, se houve leve decréscimo nessa (des)proporção no período de 10 anos, (pois em 2005 era 45,3\%), isso ocorre em razão do avanço das camadas média e baixa (IBGE, 2016, p.94).

Segundo dados da Receita Federal, apresentados no Relatório da distribuição pessoal da renda e da riqueza da população brasileira, $5 \%$ dos mais ricos detém $28 \%$ da renda e da riqueza (BRASIL, SRF, 2016). Essa disparidade apontada por ambos os documentos confirma o índice de Gini $(0,515)$ que coloca o país na indesejada colocação de 10 lugar no ranking dos países mais desiguais do mundo (PNUD 2016, p.221). 
Para o Relatório de Desenvolvimento Humano 2016, publicado pelo Programa das Nações Unidas para o Desenvolvimento (PNUD), apenas $1 \%$ da população mundial concentra $46 \%$ da riqueza mundial (PNUD 2016, p.46). Levando em consideração o Índice de Desenvolvimento Humano (IDH), embora o Brasil esteja no grupo considerado com índice "alto" - o grupo considerado "muito alto" é liderado pela Noruega e contempla os países com IDH até 0,800- o país está em 79ํl lugar no quadro geral, com IDH 0,754. Mas se considerada a variação do IDH com relação à desigualdade (IDHD), o Brasil perde 19 posições, registrando um IDHD de 0,561.

$\mathrm{Na}$ América Latina, veja-se que no grupo "muito alto" de IDH encontram-se o Chile na $38^{\text {a }}$ posição e a Argentina na 45ª posição, com os índices de IDH e de IDHD de 0,847 e 0,692, e de 0,827 e 0,698, respectivamente (PNUD 2016, p.220).

Já segundo o último Relatório de Desenvolvimento Humano Regional para a América Latina e o Caribe, a população em situação de pobreza financeira (menos de 4 dólares/dia) reduziu de $42 \%$ para 24\%, no período entre 2002 e 2013. Em termos absolutos, o número de pessoas que vive em pobreza financeira diminuiu de forma constante ao longo deste período, de quase 214 milhões para menos de 142 milhões, o que indica que cerca de 72 milhões de pessoas na região foram capazes de evitar a pobreza. Por outro lado, o tamanho da classe média (entre 10 a 50 dólares/dia) aumentou de 108 milhões de pessoas em 2002 (21\% da população total) para 202 milhões de pessoas em 2013 (35\% da população total) (PNUD Regional, 2016, p.20).

Os índices oferecem uma dimensão das dificuldades de milhares de pessoas que vivem em situação de extrema dificuldade e em constante conflito.

No Brasil, o avanço da classe média e a redução da classe em situação de pobreza também pode ser confirmado pela pesquisa Vozes da Classe Média no Brasil, que apurou, no período entre 2001 e 2011 , o crescimento da classe média de $38 \%$ para $53 \%$ do total da população. A perspectiva é de que, mantidos os critérios avaliados (taxa de crescimento e redução da desigualdade), em 2022 a classe média ocupará $57 \%$ da população total. A partir disso, a pesquisa revela que a classe média passa a ter participação expressiva no consumo das famílias, em $38 \%$, deixando o Brasil posicionado em 8o lugar no mercado consumidor, logo após a Itália (BRASIL, 2012). 
Contudo, o Relatório Regional registra um desaceleramento na redução da pobreza após a crise de 2009 e o aumento acumulado do número de pessoas vivendo em privação de rendimento é estimado em um valor próximo a 2,8 milhões de pessoas em 2015-2016 (PNUD Regional, 2016, p.26).

Mas, afinal, qual a relevância desse cenário de desigualdade quando se pretende analisar a qualidade do acesso à justiça?

Segundo o Relatório de Desenvolvimento Regional, na versão espanhola (PNUD Regional, p.26):

\begin{abstract}
El mecanismo de exclusión más directo es tal vez la violencia, cuyas motivaciones son, entre otras, la consolidación del poder político, la salvaguarda del bienestar de las élites, el control de la distribución de los recursos, la apropiación de territorios y recursos y el favorecimiento de ideologías basadas en la supremacía de una única identidad y un solo conjunto de valores. El $1 \%$ de la población mundial posee el $46 \%$ de la Riqueza. Las desigualdades de ingresos influyen en las desigualdades en otras dimensiones de bienestar y viceversa. Teniendo en cuenta la desigualdad actual, los grupos excluidos están en una posición débil para iniciar la transformación de las instituciones. Carecen de agencia (capacidad para actuar) y de voz y, por lo tanto, tienen poco peso político para influir en la política y la legislación por los medios tradicionales.
\end{abstract}

A realidade, portanto, é de uma sociedade excludente, em pleno regime democrático. Sim, mais do mesmo: a exclusão tem por motivação a preservação dos interesses das elites e o favorecimento das ideologias opressoras. Será que de fato está-se diante de um ambiente de pós-democracia? Para Rubens Casara, "o neoliberalismo aponta para a necessidade de acabar com todos os limites impostos ao exercício do poder econômico", e onde a utilização das pessoas como mercadorias ocorre sem qualquer pudor e sem qualquer limite ético ou jurídico, em plena democracia (CASARA, 2017, p.38-39).

Nesse contexto, acessar a justiça na contemporaneidade beira um privilégio e a justiça de qualidade parece estar direcionada em prol de uma aristocracia perversa que fatalmente diverge dos fundamentos republicanos. A desigualdade social, portanto, é uma evidência e condição desse cenário contemporâneo.

Para Michael Sandel, "um fosso muito grande entre ricos e pobres enfraquece a solidariedade que a cidadania democrática requer" (CASARA,2012, p.328.), de 
modo que, em um cenário de extrema desigualdade, na qual o traço de comunidade é quase inexistente, a questão que se coloca é como materializar o bem comum como valor a guiar o compromisso com o acesso à justiça? Como garantir o bem comum?

Nesse sentido, Possenti (CASARA,1991, p. 23) contribui afirmando que:

Con l'idea di bene comune non si rincorre il mito romantico di una comunità perfettamente solidale e armoniosa, ma un concetto che è vitale per l'intera filosofia pubblica e la cui assenza la rende inintelligibile. Conduciamo un esperimento mentale: si provi a cancellarne l'idea e si verifichi se sussistano ancora motivi perché gli uomini vivano insieme. Essi potranno forse ancora stipulare contratti privati, ma non esisterà più una società politica, perché non vi sarà più un bene globale intenzionato dai "cittadini" e che su essi rifluisce. Se non vi fosse un bene comune da raggiungere, la società non esisterebbe.

Portanto, e evitando deslizes para o debate raso e superficial de ideologias extremadas, a questão posta deve ser avaliada sob a perspectiva constitucional do acesso à justiça. Está-se diante de cidadãos sem cidadania. Está-se tratando da discrepância entre o discurso e a efetivação de direitos fundamentais. Está-se diante de ideologias políticas cínicas e fascistas, que envergonham a democracia e, no caso do Brasil, marcadas por um indesejado coronelismo que bebe há anos na fonte da ignorância e da inação, diante do patriarcado seleto que se revigora ao fomentar a cultura do medo e da opressão dos vulneráveis.

Sem a atenção voltada para tais obviedades é impossível compreender a natureza dos conflitos sociais e o seu correto tratamento, o que se dá, ao menos, a partir de mecanismos de solução adequados e que melhor possam ser utilizados para o restabelecimento do convívio social na perspectiva do bem comum.

De tal modo, o olhar sobre essa realidade é indispensável para a compreensão da experiência do conflito e dos seus sujeitos, no tempo e no espaço, especialmente quando parcela significativa da população vive em uma dimensão aquém da dignidade e se encontra em uma posição de extrema vulnerabilidade, que dificulta inclusive sua capacidade de reação e de transformação social. Trata-se de uma multidão sem oportunidades.

A discussão, portanto, é sobretudo de ordem constitucional e afeta sobremaneira o ambiente de acesso à justiça, diante de um verdadeiro esgotamento 
de um modelo econômico-social que alimenta uma violência simbólica a partir de acordos culturais opressores, em decorrência de uma absurda desigualdade que retroalimenta esse mesmo modelo. É a opressão do capital sobre a vida digna. Exemplo simples desse discurso é a defesa cínica de uma reforma previdenciária que afeta covardemente o cidadão trabalhador e alivia as contas das grandes empresas (GENTIL,2006). Não há como falar de regime democrático pleno nesse contexto.

De acordo com Boaventura de Sousa Santos, boa parte da litigiosidade experimentada por diversos países decorre do desmantelamento do Estado social, de modo que, "a litigação tem a ver com culturas jurídicas e políticas, mas também com o nível de efetividade da aplicação dos direitos" (GENTIL,2011, p.24).

Por outro lado, o processo demanda um alto custo para a sociedade, sem, contudo, reverter tamanho investimento através de uma prestação jurisdicional adequada às perspectivas da facticidade e sobretudo das garantias constitucionais. $\mathrm{A}$ ausência de rituais adequados de acesso à justiça atenta contra o próprio princípio da eficiência a que o Estado está comprometido.

De tal modo, para o exercício pleno da cidadania, deve o Estado Democrático de Direito, em nome do bem comum, em se tratando de rituais de solução de conflito, oferecer mecanismos adequados que assegurem a aplicação do ordenamento jurídico em respeito ao regime democrático. $E$ isso inclui o compromisso com um acesso à justiça valorado pelo bem comum, o que vai muito além das recentes reformas eficienticistas.

\section{PARA SUSPENDER OS PRÉ-CONCEITOS: UMA NOVA SUBJETIVIDADE NA PERSPECTIVA DO BEM COMUM}

Assim como não há uma hegemonia global acerca dos paradigmas sociais e institucionais predominantes (BAUMAN, 1998, p.167), difícil é oferecer, no momento, um diagnóstico para definir esse momento de transição dinâmico experimentado pelas sociedades, tanto no aspecto interno como externo. 
Para Gilles Lipovetski e Jean Serroy, as grandes utopias perderam o essencial de sua credibilidade e aquela expectativa do futuro, própria da modernidade, cedeu passagem ao superinvestimento no momento presente e, a curto prazo, ao tempo em que um novo regime cultural, que ele chama de hipermodernidade, floresce com a perspectiva de se remodelar a lógica do individualismo e do consumismo, cuja principal instância é a economia e seu poder multiplicado (BAUMAN, 2011, p.13-14).

Neste sentido são os questionamentos de Gilles Lipovetski (BAUMAN, 2005, p.59-60).

\begin{abstract}
Esgotamento de uma cultura hedonista e vanguardista ou surgimento de um novo poder renovador? Decadência de uma época sem tradição ou revitalização do presente por meio de uma reabilitação do passado? Novo modo de continuidade na trama modernista ou descontinuidade? Peripécia na história da arte ou destino global das sociedades democráticas? Nós nos recusamos aqui de circunscrever o pós-modernismo num quadro regional, estético, epistemológico ou cultural: caso se trate de pós-modernismo, ele deverá provocar uma onda profunda e geral na escala do todo social, uma vez que na verdade vivemos um tempo em que as oposições rígidas se esfumam, em que as preponderâncias se tornam fluidas, em que a inteligência do momento exige que se ressaltem correlações e homologias.
\end{abstract}

A sociedade contemporânea, portanto, dotada de uma angustiante urgência e de uma mutação extremamente volátil, é uma sociedade produtora de conflitos de massa, de consumo de massa e, em decorrência disso, caracterizada por uma conflituosidade massificada, absolutamente associada aos anseios de uma economia voraz (SANTOS, 2016, p.37). Nesse cenário de uma nova modernidade, é possível observar novos totalitarismos, em pleno ambiente democrático. Ocorre que não se pode observar a existência do "indivíduo" em uma sociedade totalitária (CASTORIADIS, p.26).

Giorgio Agamben afirma que, neste ambiente em que o capitalismo vive sua forma extrema, todas as coisas são exibidas na sua separação de si mesmas, de modo que espetáculo e consumo são duas faces de uma única impossibilidade de usar (CASTORIADIS, 2007, p.71). Nessa mesma perspectiva, na observação de Guy Debord, a origem do espetáculo é a perda da unidade do mundo, em que as "multidões solitárias" estão ligadas pelo próprio centro que os mantém isolados: "o espetáculo 
reúne o separado, mas o reúne como separado" (CASTORIADIS,1997, p.23). Tal é a caracterização da sociedade-rebanho, na qual todos querem o mesmo e todos são iguais (NIETZSCHE, 2004, p.29).

Para Jacques Chevallier, ainda, haveria um novo individualismo, que acentua de forma narcisista a realização pessoal como principal valor da vida (NIETZSCHE, 2009, p.18), próprio de um mundo invadido pela universalização da cultura mercantil, que se apodera da vida social, do comportamento do homem e de suas atividades, onde se observa a infantilização dos consumidores e o empobrecimento da vida social e intelectual.

Sob uma outra ótica, segundo Gisele Citadino, o retorno ao mundo da ética, do direito e da política já não permite qualquer referência a um sujeito individual ideal, pois quando a figura do outro é representada através das imagens do competidor e do inimigo, não pode haver política de cooperação democrática (NIETZSCHE, 1999, p.76). Nesta perspectiva, o eu isolado passa a ser substituído por um consenso ético comunitário, orientado pela subjetividade de sua própria visão de mundo, que busca a constituição de um nós, animado por um sentimento de destino compartilhado (NIETZSCHE, 1999, p.133).

Nesse aspecto, as concepções de um novo modelo estatal vão além das discussões atinentes àquele formato aspirado por liberais e comunitários, na análise de Gisele Citadino, já que neste novo ambiente a figura do indivíduo solitário é substituído pela intersubjetividade, dadas as relações linguísticas e comunicativas estabelecidas entre os homens que permitem a renúncia de um direito meramente instrumental para estabelecer uma necessária e intrínseca relação entre ética e direito (NIETZSCHE, 1999, p.219-220).

Essa superação dos maniqueísmos clássicos é a proposta de Antonio Negri e Michael Hardt, para quem a democracia da multidão só pode ser pensada ou somente é possível sob a perspectiva do que é comum ou compartilhado, tanto no aspecto material, das riquezas naturais (contexto ecológico), e no aspecto da produção social, como o conhecimento, a informação e os afetos (contexto socioeconômico) (NIETZSCHE 2016, p.8). 
Nesta perspectiva, o conceito de comum centra-se "nas práticas de interação, cuidado e coabitação num mundo comum, promovendo as formas benéficas do comum e limitando as prejudiciais", já que, segundo os autores, "a própria produção capitalista contemporânea, ao atender às suas próprias necessidades, possibilita e cria as bases para uma ordem social e econômica alicerçada no comum", de modo que o cerne da produção biopolítica supera a ideia de produzir objetos para sujeitos, para abrir espaço para a produção da própria subjetividade: "a multidão se constitui compondo no comum as subjetividades singulares que resultam desse processo (NEGRI; HARDT, 2016, p.10-11).

A ideia de comunhão proposta por Negri e Hardt não significa unidade ou uniformidade, mas sim "o encontro" das singularidades, que por sua vez produz um novo comum e novas singularidades (NEGRI; HARDT, p.208), o que ocorre, segundo os autores, a partir de um sentimento de amor em seu aspecto filosófico e político, e a partir dos elementos de pobreza enfatizados a partir da solidariedade, do cuidado com os outros, da cooperação e da criação de comunidade (NEGRI; HARDT, p.204).

Trata-se de uma análise que muito se aproxima do ideal de igualdade como primado elementar da democracia e como objetivo da República no Brasil, estampado no art.3o inciso IV da Constituição de 1988, na defesa de uma convivência pacífica das diferentes identidades. Neste sentido, Negri e Hardt, antes de (re) (i) inovarem em suas proposições, levam a sério esse argumento e reforçam a importância do encontro da alteridade, para criação de um novo agrupamento marcado pela contínua metamorfose de cada singularidade no comum (NEGRI; HARDT, p.212). Seria possível, assim, segundo Negri e Hardt, para além do individual e do coletivo, pensar em uma nova e reforçada subjetividade, que respeita as diferenças de uma sociedade pluralista e aposta no sentimento político comum cuidado, solidariedade e cooperação para a construção de um bem comum.

Do que parece orbitar no campo do ideal para o que é possível materializar, Michael Sandel oferece perspectivas concretas para o que poderia ser uma nova política do bem comum. O autor aposta no sentimento de comunidade, de preocupação com o todo e na dedicação ao bem comum, para tornar viável o cultivo da solidariedade e o sentimento de responsabilidade mútua em uma sociedade 
pluralista (2012, p.325). Aposta também na imposição de limites morais aos mercados, protegendo as normas que não podem sofrer a interferência do poder econômico, sob pena de permitir que "o mercado reescreva as normas" (NEGRI; HARDT, 2012, p.327). Sandel aposta, ainda, na reconstrução da infraestrutura da vida cívica, em combate à desigualdade social, que segundo o autor "corrói a virtude cívica", relacionando justiça distributiva e o bem comum (NEGRI; HARDT, 2012, p.328-329).

Sob outro aspecto, mesmo que seja possível uma nova subjetividade que defenda o bem comum, e que sua materialização viria a promover uma vida digna indistinta, isso não significaria a aniquilação natural do conflito. Diante disso, a concepção de que é possível conviver com uma nova subjetividade muda radicalmente as bases alicerçadas no processo individualista nascido no âmago do liberalismo do século XIX.

Nem individual, nem coletivo, mas sim uma nova subjetividade para o que é comum exige. A partir disso, novas ou renovadas formas de rituais devem ser lançadas para que, de maneira adequada, possam tratar dos conflitos advindos desta nova subjetividade.

Resta avaliar, portanto, quais implicações que essa concepção sobre o bem comum sobre o processo civil na atualidade, enquanto instrumento de materialização de acesso à justiça.

\section{PARA CONCRETIZAR: O "BEM COMUM" COMO VALOR E O ACESSO À JUSTIÇA COMO COMPROMISSO}

Para o modelo atual de democracia, não obstante a Constituição Federal de 1988 defenda a "promoção do bem de todos" (art.3ํ, inciso IV) e o novo CPC venha a defender o bem comum como critério de aplicação do ordenamento jurídico (art.8º), é preciso avaliar o modo como o conflito social vem sendo tratado na atualidade na perspectiva do acesso à justiça e suas implicações sobre o processo civil. 
E o tratamento do conflito social e o modo como o Judiciário se organiza para fazê-lo vem há muito na linha do que Mauro Cappelletti já defendia para a universalização do acesso à justiça e que ainda merece ser analisado a partir do acesso dos menos favorecidos, da proteção dos direitos difusos e coletivos e da efetivação dos procedimentos alternativos à jurisdição (CAPPELLETTI; GARTH, 1988, p. 31).

Para a população mais vulnerável, ainda que as defensorias públicas e as assistências judiciárias gratuitas das universidades sejam uma realidade, não há uma hegemonia de atendimento em todo o país, na medida em que muitos sertões, e nos quais o cidadão mais necessita, não foram alcançados por tais instituições.

Com relação às Defensorias Públicas, sem dúvida foi significativa a autonomia funcional, administrativa e financeira advinda com a Emenda 45/2004. Contudo, ainda há um descompasso entre os orçamentos da Defensoria, Ministério Público e Judiciário (SANTOS, 2011, p.53) Não bastasse isso, ainda que as Defensorias no âmbito estadual estejam em maior proporção na comparação com as Defensorias do âmbito federal, a cobertura do serviço prestado ainda está bastante limitada e não alcança boa parte da população vulnerável (SANTOS, 2011, p.54).

No âmbito da Defensoria Pública da União, o atendimento abrange, por exemplo, grupos de vulneráveis integrados por povos indígenas, moradores de rua, imigrantes e refugiados, trabalhadores escravos, entre outros, cuja renda não ultrapasse dois mil reais (DPU, 2017). Segundo o último mapa de atendimento divulgado pela Instituição, durante o ano de 2015 foi atendido pouco mais de 1,5 milhão de pessoa (DPU, 2015, p.45). Nesta perspectiva, se considerados os dados da desigualdade social, a população de baixa renda orbitaria em torno de $40 \%$ da população brasileira (levando-se em conta os percentuais da classe mais rica e da classe média, de $10 \%$ e 50\%, respectivamente), o que significa dizer que a assistência jurídica integral e gratuita, garantida pelo art.134 da Constituição Federal, está realmente distante da realidade para uma sociedade fatalmente desigual que ultrapassa 200 milhões de habitantes em 2015 (IBGE, 2015).

Os dados são alarmantes, na medida em que a demanda conflituosa decorrente desse quadro desconcertante da desigualdade social no país vai escoar 
justamente pelas vias das Defensorias Públicas. Logo, sem a presença da Defensoria é impossível materializar o exercício pleno da cidadania quando se trata de acesso à justiça.

Quanto aos conflitos que afetam uma multiplicidade de cidadãos, ainda prepondera a via processual individual e isolada em juízo para a satisfação de uma pretensão que sobretudo é coletiva. E para além do que já foi dito em obra recente a respeito da falta de sintonia entre uma pretensão de titularidade da massa e o processo apresentar caráter individualista (SANTOS, 2016), é preciso avaliar o que de fato é possível materializar, no âmbito processual, quanto à perspectiva do bem comum.

O fato é que as últimas reformas, o que inclui o novo Código de Processo Civil, preconizam o processo individual em nome da eficácia e pouco evoluíram no campo do processo coletivo. Evidência dessa lógica é o veto sobre o art.333 do novo CPC, que previa a conversão de ações individuais em ação coletiva (art.333). O veto presidencial acabou privilegiando o uso do incidente de resolução de demandas repetitivas (IRDR, art.976), em detrimento da medida de conversão, mantendo, assim, uma visão já cultuada no Brasil que sobressalta as ações individuais e menospreza as ações coletivas.

Quanto à necessidade de renovação e adequação dos procedimentos, é preciso, ainda, atentar-se para os meios alternativos à jurisdição que se valem do consenso para a efetivação do acesso à justiça. Com este viés, políticas públicas têm sido desencadeadas para o estímulo e engajamento do uso efetivo da mediação, conciliação e arbitragem. Contudo, a verdade é que tais métodos ainda não foram internalizados de fato na cultura jurídica.

Somente no ano de 2015 três novas leis trataram do assunto: o novo CPC (Lei 13.105/2015), a Lei 13.129/2015, que atualizou a Lei de Arbitragem (Lei 9.307/1996), e a Lei de Mediação (13.140/2015). Mas no imaginário jurídico-social, a verdadeira justiça ainda é a de toga, razão pela qual a busca pelo consenso não obteve o devido respeito da comunidade jurídica, seja no ambiente processual, seja na via administrativa. 
Por outro lado, o Judiciário tem buscado demonstrar sua eficácia por meio de índices de produtividade, revelados nos últimos anos pelo Relatório Justiça em Números do Conselho Nacional de Justiça. Contudo, o patamar de eficácia em termos quantitativos no ambiente da gestão pública não se confunde com o atendimento dos fins sociais, das exigências do bem comum e da dignidade do cidadão, especialmente considerando o escopo constitucional da efetividade da prestação jurisdicional, conceito este tão caro quando se coloca como condição de acesso à justiça.

O fato é que a efetividade da prestação jurisdicional está além das estatísticas, pois o acesso à justiça, na altura dos direitos fundamentais, não se apresenta no ranking dos tribunais, mas no dia-a-dia do cidadão frente ao conflito tratado e estabilizado.

Daí a importância do estímulo ao consenso e de procedimentos que apostem na abertura e na retomada do diálogo como instrumento de autonomização e emancipação do cidadão na busca do acesso à justiça. Tal perspectiva, ao contrário do que possa ser compreendido, não desmerece o ambiente jurisdicional, mas sim valoriza ainda mais a jurisdição como ambiente caro e complexo, para o qual só devem ser direcionados somente os conflitos de interesses cuja solução não possa ocorrer pela via do consenso, onde o diálogo não tenha capacidade de tratar e solucionar o problema.

Assim, sob um outro aspecto, a partir de uma perspectiva constitucional de bem comum e com vistas à preservação da dignidade humana, é preciso também reavaliar os fundamentos do processo contemporâneo, levando em consideração seus elementos subjetivos e objetivos.

Com relação aos elementos subjetivos, a partir da análise dos sujeitos processuais, segundo José Miguel Garcia Medina, interessa não apenas o modo como os sujeitos se relacionam, mas devem ser considerados os atributos dos sujeitos do processo, como entes que integram a sociedade e que manifestam sua condição humana, social, econômica, etc (SANTOS, 2016, p.115).

Neste sentido, Medina vai valorizar a interação e a comunicação entre os sujeitos e o órgão jurisdicional, destacando a imprescindibilidade de que tais sujeitos estejam em condições de compreender e de serem compreendidos, o que significa 
dizer que, ao proferir uma decisão, o juiz deverá ter a consciência de que, durante o desenvolvimento do processo, conheceu efetivamente as partes e o contexto socioeconômico em que se encontram e, por fim, as justificativas dadas por ele para a tomada de decisão estejam não só sob o prisma jurídico, mas também sob a perspectiva social (MEDINA, 2016, p.116).

Nesse patamar, o princípio da cooperação se destaca nas normas fundamentais, tal qual se observa no art.6 $6^{\circ}$ do novo CPC. Tal norma tem a solidariedade em sua latência, o que constitui caminho frutífero para a obtenção do bem comum. Logo, o bem comum como valor deve atravessar todo o rito processual, seus pressupostos e garantias.

Para Aristóteles, a justiça é a virtude mais completa, porque a "pessoa que a possui pode exercer sua virtude não só em relação a si mesmo, como também em relação ao próximo" (ARISTÓTELES, 2003, p.105), de modo que o bem comum é condição da própria justiça, ou seja, o aspecto democrático e comunitário é inerente à plenitude do acesso à justiça.

Portanto, é preciso adaptar o processo civil à sua dimensão histórica. Tratar de conflitos contemporâneos com as mesmas ferramentas dos séculos passados atenta contra a própria concepção de justiça. Se o processo se fundou a partir de princípios privatísticos ou individualistas, a materialização do acesso à justiça na contemporaneidade está a exigir o desapego de seus dogmas.

\section{CONCLUSÃO}

É vasta a pesquisa jurídica acadêmica acerca dos direitos fundamentais e sua eficácia e, não obstante isso, é angustiante a constatação de que, na prática, o mundo teórico pouco tem ecoado sobre a sociedade no que se refere ao acesso à justiça. Ou o conceito está divagando em um mundo paralelo, reproduzindo e sustentando, ainda, a compreensão de direito dissociado do fato/realidade, ou a aposta da teoria segue por rota equivocada. 
Sob outro aspecto, sendo fiel ao momento em que vivemos, falar sobre acesso à justiça nesse contexto de pós ou hipermodernidade, exige um olhar sobretudo horizontal sobre a realidade social, sob pena de restarem preconizadas as exigências do bem comum como critério de aplicação do ordenamento jurídico em um ambiente paradoxal e culturalmente descompassado, no qual os mecanismos de acesso à justiça não honram com seu compromisso e não servem à sociedade, sobretudo desigual.

Por outro lado, as estatísticas da desigualdade denotam a nossa dificuldade de pensarmos coletivamente ou solidariamente. Somos uma soma de indivíduos e não uma coletividade de fato. Formamos, portanto, uma massa não conectada, facilmente controlada e manipulada por discursos estrategicamente formulados para atender aos propósitos do poder instituído.

Nesse contexto, não há dignidade na cidadania vulnerável. Não há como materializar o bem comum como valor a guiar o acesso à justiça quando o cidadão não dispõe de assistência jurídica adequada, integral e gratuita; quando o cidadão é submetido a um procedimento que não seja compatível com a natureza do seu conflito; quando conflitos desiguais em sua natureza, produtores de pretensões especiais, são tratados ou conduzidos por rituais-padrão.

Por isso, processo constitucionalmente adequado é aquele que não cria obstáculos de acesso à justiça, ao tempo em que promove a dignidade do cidadão e respeita as desigualdades do conflito, em meio as contingências da sociedade contemporânea. Não desejar enfrentar essa problemática é deixar evidente a preferência pelo discurso em detrimento da efetividade dos direitos fundamentais.

$\mathrm{Na}$ perspectiva do acesso à justiça, os rituais devem ser guiados pela construção do bem comum, concebido como senso de comunidade, em busca do que seja digno para uma nova subjetividade, nem individual e tampouco coletivista, mas atenta aos pluralismos do contemporâneo e que respeita as diferenças, sob os critérios do cuidado, da solidariedade e da cooperação.

Isso porque é possível apostar na transformação social pelo ritual. Os rituais ao longo da sua materialização são capazes de internalizar uma cultura de acesso à justiça para uma nova subjetividade que, pautada no bem comum, tenha seu propósito 
voltado para a democracia e os ideais de cidadania e dignidade preconizados pela nossa Constituição.

Se o processo civil nasceu sob a égide de uma época que desconhecia sobretudo a concepção de direitos humanos, preocupação esta surgida mais tarde, deverá renascer ou refazer-se para o século XXI. Caso contrário, o processo manterse-á nos labirintos forenses resolvendo lides sem resolver os conflitos e o exercício efetivo do acesso à justiça, como expressão de cidadania plena, continuará orbitando apenas os limites da academia.

Nesse sentido, pensar o acesso à justiça na contemporaneidade requer uma abertura e uma postura sobretudo atenta à necessidade de remodelação de rituais que apostem nos valores sobretudo constitucionais, inerentes à ordem democrática. Se transformar o conflito social em uma experiência positiva é uma perspectiva necessária, tendo o senso de comunidade suficientemente claro para uma nova subjetividade, é possível afirmar que o processo assumirá a parcela de compromisso que the cabe, qual seja o de promover acesso à justiça como exercício pleno de cidadania, na perspectiva do bem comum.

\section{REFERÊNCIAS}

AGAMBEN, Giorgio. Profanações. São Paulo: Boitempo, 2007.

ARISTÓTELES. Ética a Nicômaco. São Paulo: Martin Claret, 2003.

BAUMAN, Zygmunt. O mal estar da pós-modernidade. Rio de Janeiro: Zahar, 1998.

BRASIL. Decreto-Lei 4657, de 4 de setembro de 1942. Lei de Introdução às normas do Direito Brasileiro. Disponível em: <http://www.planalto.gov.br/CCivil_03/DecretoLei/Del4657compilado.htm>. Acesso em: 23 Fev.2017

Lei 13.105, de 17 de março de 2015. Código de Processo Civil. Disponível em: <http://www.planalto.gov.br/ccivil_03/_ato2015-2018/2015/lei/113105.htm>. Acesso em: 23 Fev.2017

. Lei 13.129, de 26 de maio de 2015. Altera a Lei no 9.307, de 23 de setembro de 1996, entre outras. Disponível em: < 
http://www.planalto.gov.br/ccivil_03/_Ato2015-2018/2015/Lei/L13129.htm>. Acesso em: 23 Fev. 2017.

Lei 13.140, de 26 de junho de 2015. Dispõe sobre a mediação entre particulares como meio de solução de controvérsias e sobre a autocomposição de conflitos no âmbito da administração pública, entre outras. Disponível: < http://www.planalto.gov.br/ccivil_03/_ato2015-2018/2015/Lei/L13140.htm>. Acesso em: 23 Fev. 2017.

. Secretaria da Receita Federal. Relatório da distribuição pessoal da renda e da riqueza da população brasileira. Disponível em: <http://www.fazenda.gov.br/centrais-de-conteudos/publicacoes/transparenciafiscal/distribuicao-renda-e-riqueza/relatorio-distribuicao-da-renda-2016-05-09.pdf>, Acesso em: 22 Mar. 2017

. Vozes da Classe Média. Disponível em <http://www.sae.gov.br/site/wpcontent/uploads/Cartilha-Vozes-Classe-Media.pdf>, Acesso em: 26 Mar.2014. Disponível em: https://issuu.com/sae.pr/docs/cartilha-vozes-classe-media_vers_o. Acesso em: 10 Jul. 2017.

CAPPELLETTI, Mauro; GARTH, Bryant. Acesso à Justiça. Porto Alegre: Fabris, 1988.

CASARA, Rubens R. R. Estado Pós-democrático - neo-obscurantismo e gestão dos indesejáveis. Rio de Janeiro: Civilização Brasileira, 2017.

CASTORIADIS, Cornelius. A instituição imaginária da sociedade. Rio de Janeiro: Paz e Terra, 1982.

CHASE, Oscar G. Direito Cultura e Ritual: Sistemas de Resolução de conflitos no contexto da cultura comparada. Tradução de Sérgio Arenhart, Gustavo Osna. São Paulo: 2014.

CHEVALLIER, Jacques. O Estado pós-moderno. Belo Horizonte: Forum, 2009.

CITADINO, Gisele. Pluralismo, Direito e Justiça Distributiva. Elementos da Filosofia Constitucional Contemporânea. Rio de Janeiro: Lumen Juris, 2004.

DEBORD, Guy. A sociedade do espetáculo. Rio de Janeiro: Contraponto, 1997.

DPU. Assistência Jurídica Integral e Gratuita no Brasil: Um panorama da atuação da Defensoria Pública da União. Disponível em: http://www.dpu.def.br/images/stories/arquivos/PDF/Mapa_dpu_2015_web.pdf Acesso em 10 Jul. 2017. 
DPU. Resolução 134, de 7 de dezembro de 2016. Institui o valor econômico para a assistência integral e gratuita. Disponível em: http://www.dpu.def.br/legislacao/infoleg/37049-02-05-2017-dpu-no-diario-oficial-dauniao-e-no-bei>. Acesso em 12 Jul. 2017.

GADAMER, Hans-Georg. Verdade e Método I. Petrópolis: Vozes, 2004.

GADAMER, Hans-Georg. O problema da consciência histórica. São Paulo: Fundação Getúlio Vargas, 2003.

GARAPON, Antoine. 0 guardador de promessas: justiça e democracia. Lisboa: Instituto Piaget, 1996.

GENTIL, Denise Lobato. A Política Fiscal e a Falsa Crise da Seguridade Social brasileira - Análise financeira do período de 1990 a 2005. Tese de Doutorado. Disponível em: <https://drive.google.com/file/d/OB8uQD54Gv87oTy11TkhIY0hRbm8/view>, Acesso em 20 Mar. 2017.

HARDT, Michael; NEGRI, Antonio. Bem-estar comum. Rio de Janeiro: Record, 2016.

IBGE. Síntese dos Indicadores Sociais. Uma análise das condições de vida da população brasileira. 2016. Disponível em: http://biblioteca.ibge.gov.br/visualizacao/livros/liv98965.pdf. Acesso em: fev 23. 2017

Federação brasileira em 01.07.2015. Disponível em: 01.07.2015<http://www.ibge.gov.br/home/estatistica/populacao/estimativa2015/estim ativa_dou.shtm>. Acesso em: 11 Jul.2017.

LIPOVETSKI, Gilles. A era do vazio: ensaios sobre o individualismo contemporâneo. São Paulo: Manole, 2005.

; SERROY, Jean. A cultura-mundo - resposta a uma sociedade desorientada. São Paulo: Companhia das Letras, 2011.

MARINONI, Luiz Guilherme. Teoria Geral do Processo. $7^{a}$ ed. São Paulo: Revista dos Tribunais, 2013.

MEDINA, José Miguel Garcia. Direito Processual Civil Moderno. $2^{\underline{a}}$ ed. São Paulo: Revista dos Tribunais, 2016.

NERY JR., Nelson. Comentários ao Código de Processo Civil. 16ª ed. São Paulo: RT, 2016.

NIETZSCHE, Friedrich. Assim falou Zaratustra. São Paulo: Martin Claret, 2004. 
ONU. PNUD. Relatório de Desenvolvimento Humano 2016. Disponível em: < http://hdr.undp.org/sites/default/files/2016_human_development_report.pdf>, Acesso em: 22 Mar. 2017.

$\overline{\text { América }}$ Latina e o Caribe. Disponível em:
<http://www.br.undp.org/content/dam/brazil/docs//DH/undp-br-progressomultidimensional-2016.pdf>, Acesso em: 22 Mar. 2017

POSSENTI, Vittorio. Le società liberali al bivio. Roma: Marietti, 1991.

SANDEL, Michael J. Justiça - O que é fazer a coisa certa. Rio de Janeiro: Civilização Brasileira, 2012.

SANTOS, Boaventura de Sousa. Para uma revolução democrática da justiça. São Paulo: Cortez, 2011.

SANTOS, Karinne Emanoela Goettems dos. A questão de fato e a questão de direito a partir de uma perspectiva hermenêutica. 2006. 222 f. Dissertação (Mestrado em Direito). Programa de Pós-Graduação em Direito, Universidade do Vale do Rio do Sinos (UNISINOS), São Leopoldo, 2006.

. Processo Civil e Litigiosidade - Para além da jurisdição dos conceitos sem coisas. Rio de Janeiro: Lumen Juris, 2016.

SILVA, Ovídio Baptista da. Processo e Ideologia - o paradigma racionalista. $2^{\mathrm{a}}$ ed. Rio de Janeiro: Forense, 2006. 